\title{
Undergraduate Teaching Assistants
}

Carla M. Strickland-Hughes (she / her / hers)

Assistant Professor

Psychology Department

College of the Pacific 


\section{Name one significant difference between in-person learning and remote learning.}




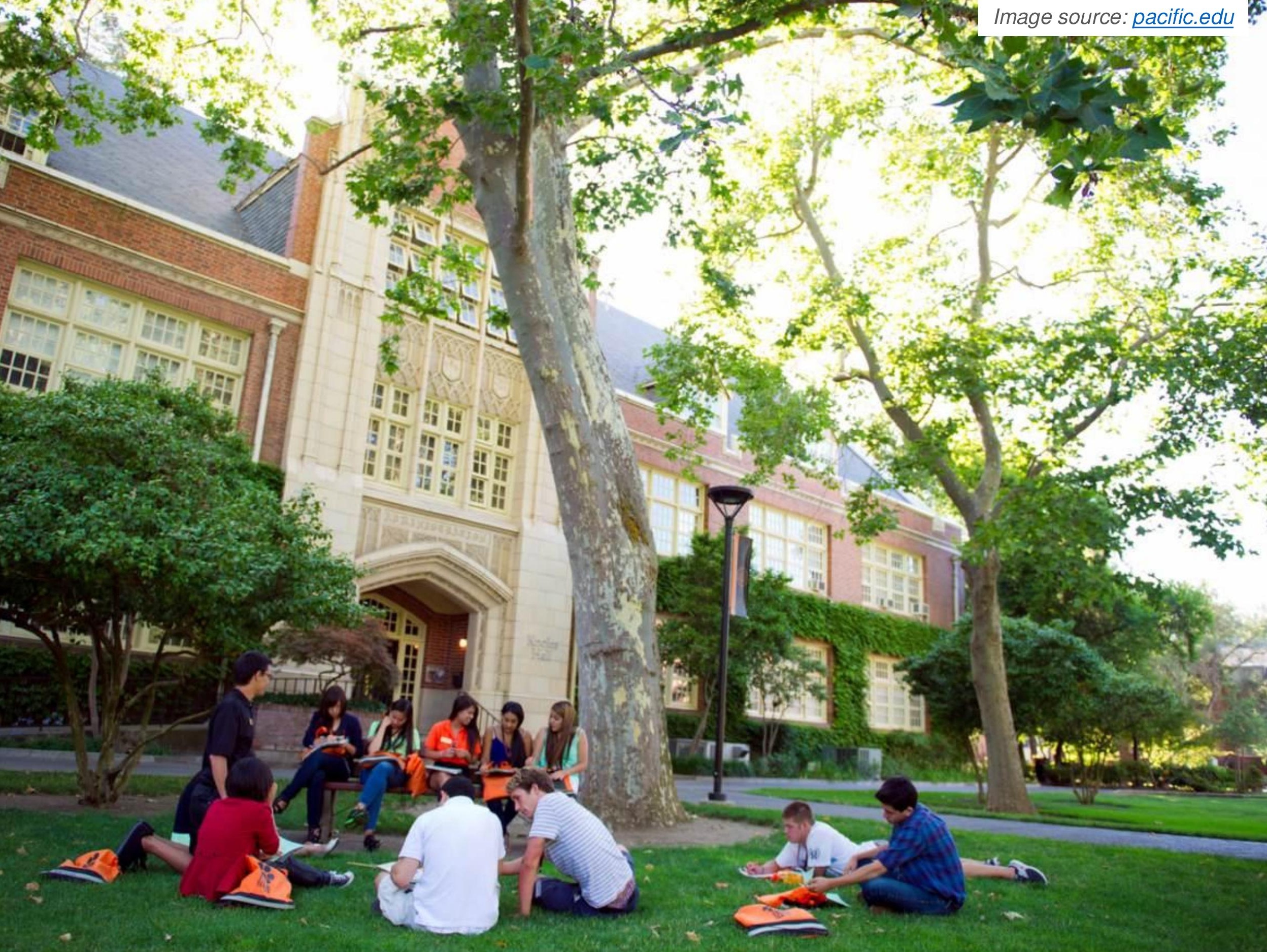




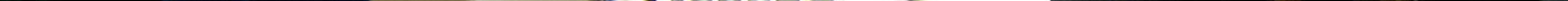




\section{Developmental Psychology Fall 2020}

$\underline{N=82 \text { students }}$

$\star 70 \%$ prefer she / her / hers

$\star 38 \%$ employed full or part time

$\star 31 \%$ Hispanic / Latine

$\star 29 \%$ 1st gen. \& $42 \% 1+$ parent college grad+

$\star 22 \%$ psych majors
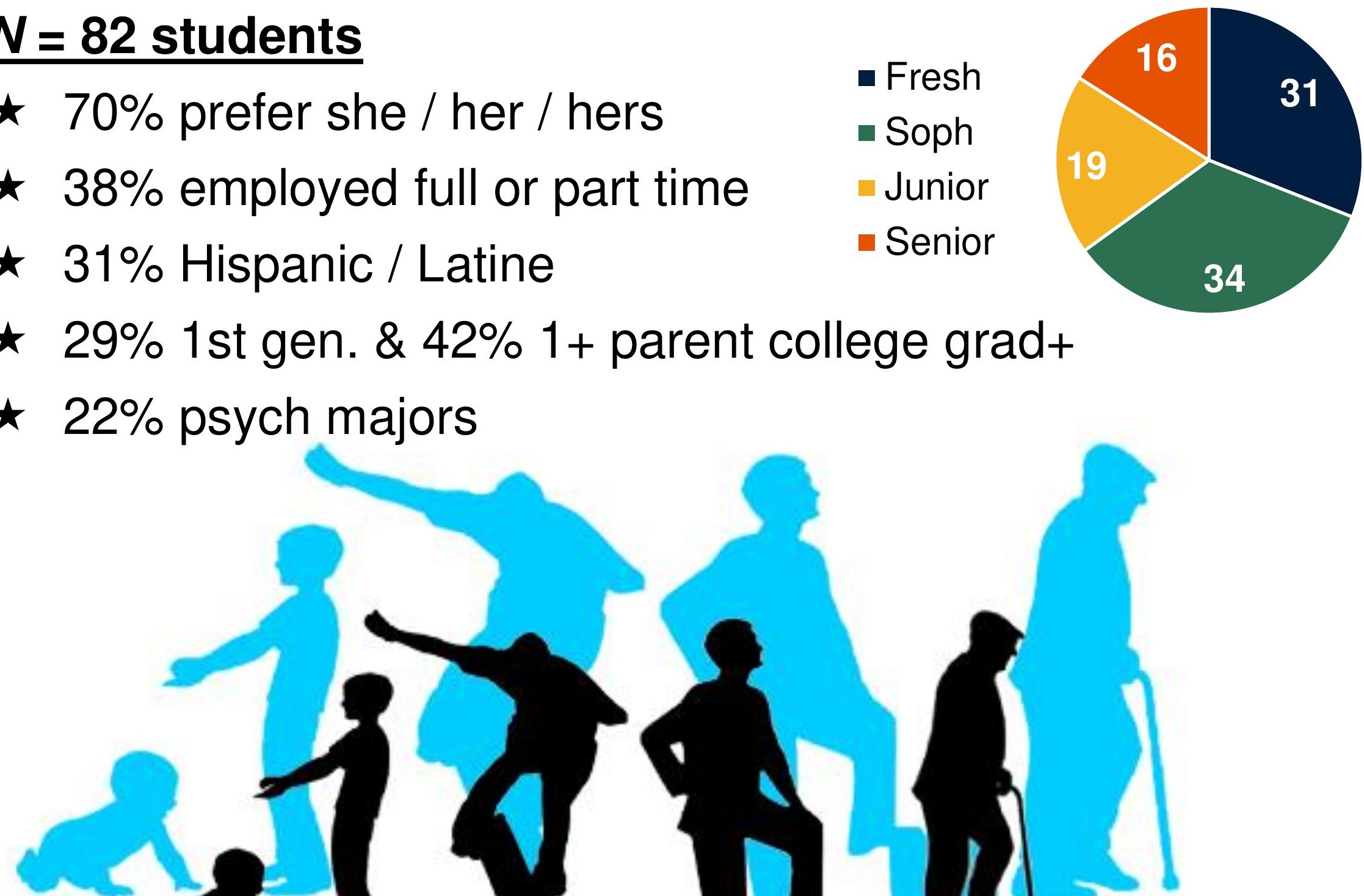


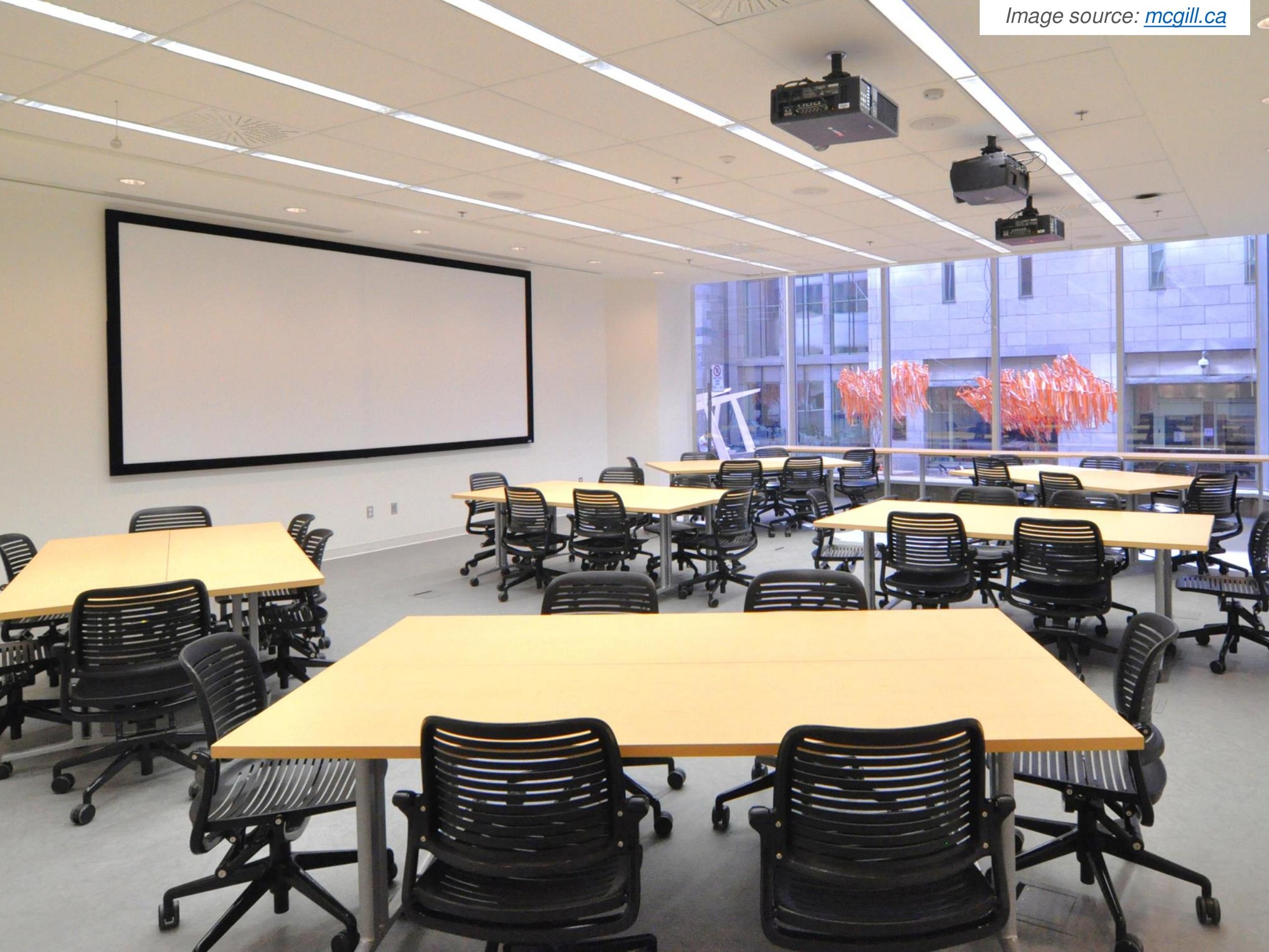




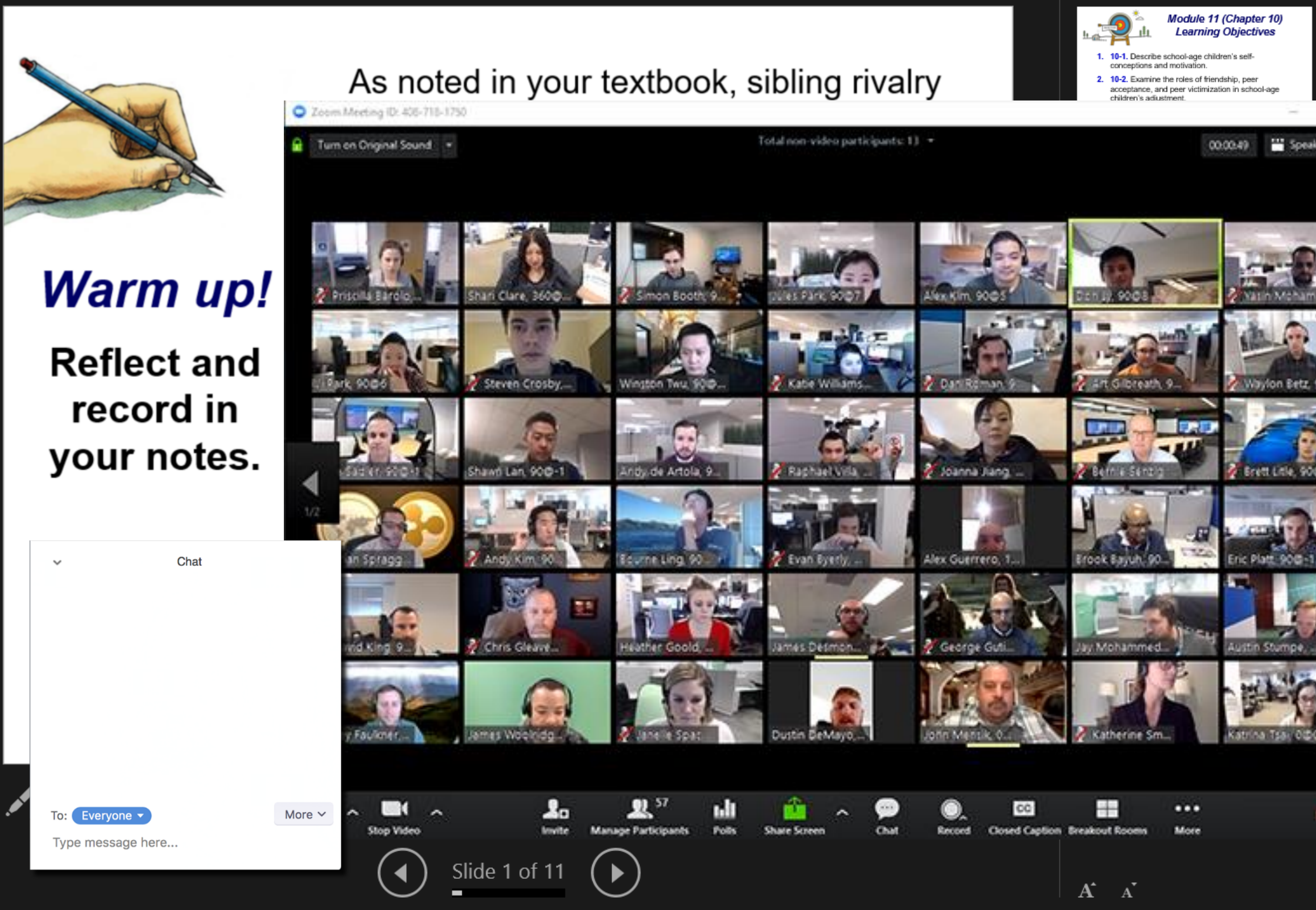




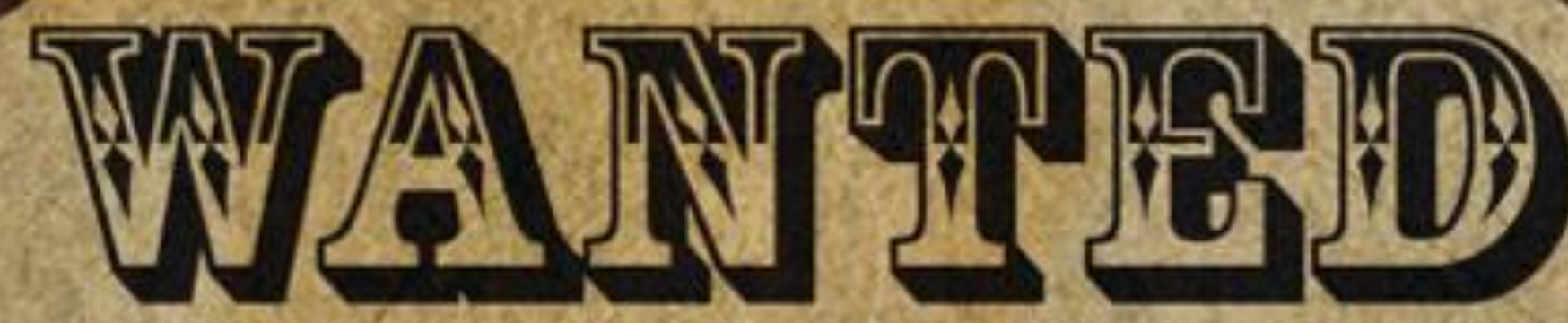

\section{Undergraduate}

Teaching Assistants

for Developmental

Psychology 


\section{Undergraduate Teaching Assistants $(\boldsymbol{N}=\mathbf{6})$}

$\star$ Weekly team meetings

- Agenda ("lesson plan")

- Quality control

- Share successes

- Teaching training

$\star$ Small group discussions

$\star$ Time log \& reflection papers

$\star$ Above-and-beyond

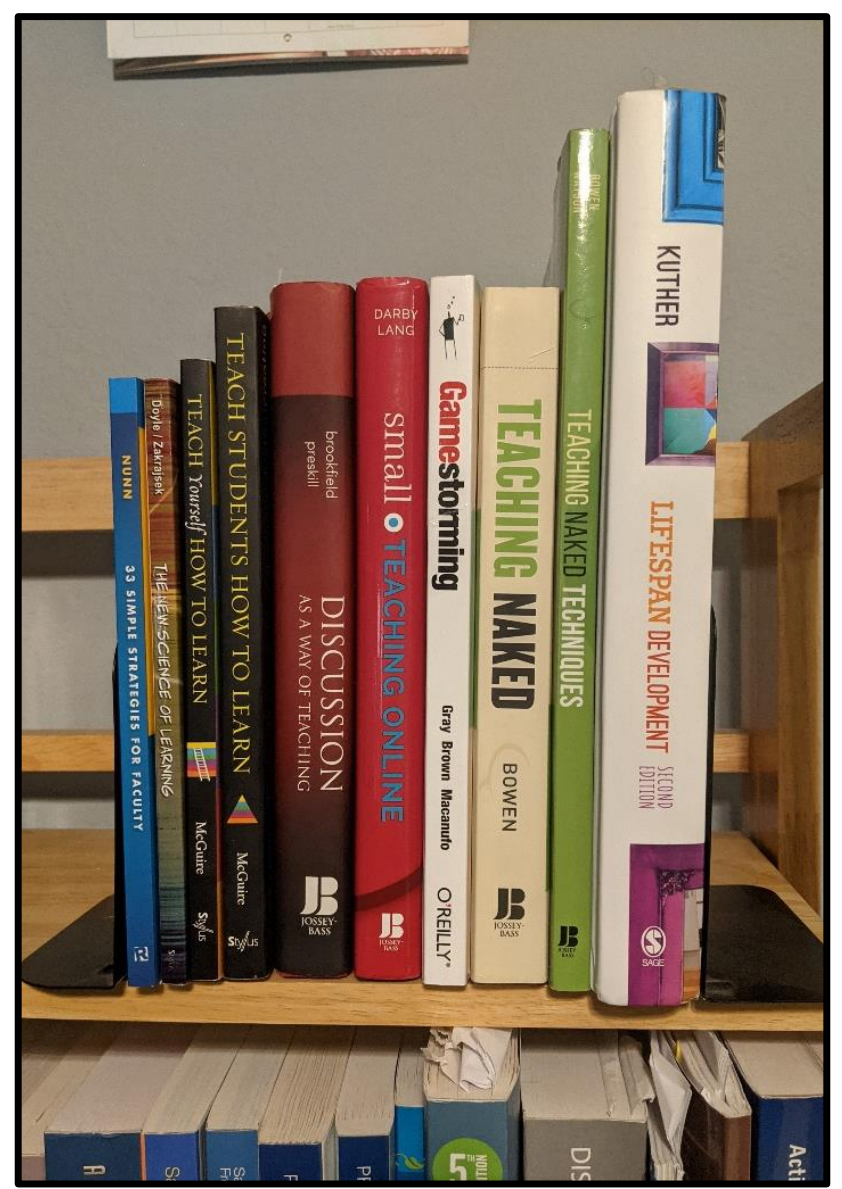


"Democratic Discussions"

$\star$ Groups of 6-8 students

$\star 45$ minutes

$\star$ Active learning
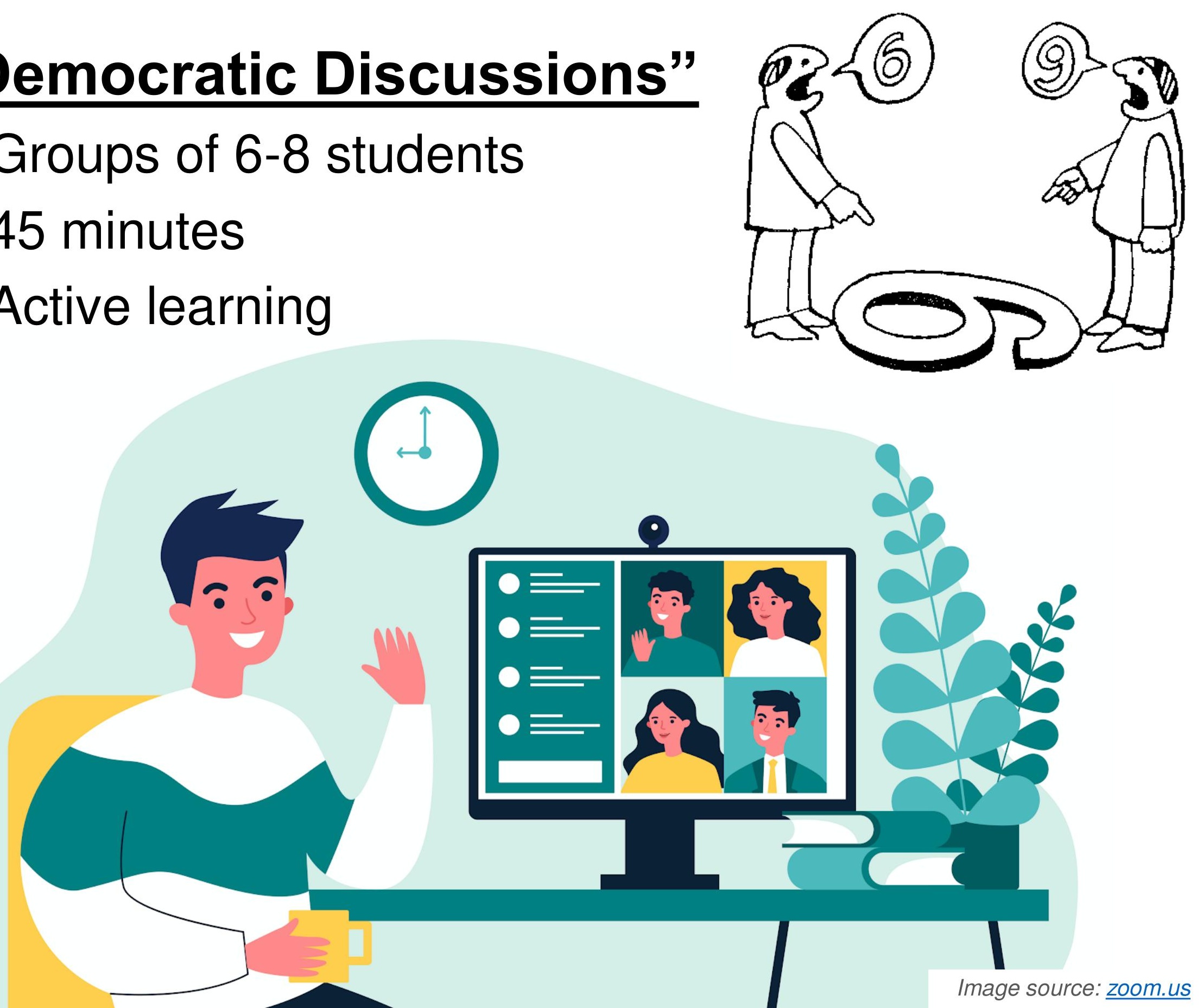


\section{Mid-semester feedback}

$\star$ Week 6

$\star$ Required, but anonymous

$\star 78$ out of 82 students (95\%) responded 


\section{The Teaching Assistant for my small group}

$\star$ Nice, welcoming ( $n=35 ; 45 \%)$

$\star$ Inclusive, facilitates collaboration, encourages everyone to participate $(n=21,27 \%)$

$\star$ Helpful $(n=17,22 \%)$

$\star$ Clear, responsible, direct $(n=11,14 \%)$

$\star$ Engaging, fun $(n=8,10 \%)$

$\star$ Understanding, patient $(n=8,10 \%)$

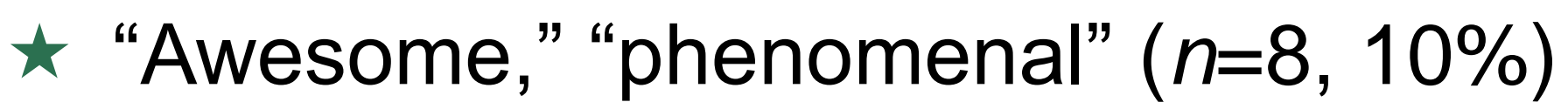




\section{The Thursday group zoom calls}

$\star$ Fun / engaging ( $n=28 ; 36 \%)$

$\star$ Inclusive, welcoming, collaborative ( $n=25 ; 32 \%)$

$\star$ Help learn $(n=20 ; 26 \%)$

$\star$ Broaden perspective $(n=14 ; 18 \%)$

$\star$ Interactive, increased participation ( $n=14 ; 18 \%)$

$\star$ Not productive or helpful $(n=4 ; 5 \%)$

$\star$ Awkward, quiet, uncomfortable $(n=4 ; 5 \%)$ 
... gives me an opportunity to work in a group setting, where I understand that everyone's voice, including mine, are important. The lectures also allows me to understand other people's ideas that I would have never thought of it myself, training me to be more open-minded.

The closest thing to being on a campus. I don't talk to anyone else in my other zoom lectures so getting to talk with people that I see at campus is really cool and the time always goes by fast instead of slow and dreading.

... are very helpful because we are in small groups and gets us to interact with one another which gives those that have a hard time talking with other or making friends an opportunity to step out of their shell and gain those connections with those in their class. 


\section{End-of-semester feedback}

$\star 42$ out of 82 students (51\%) responded 


\section{Which aspects of the course wo
recommend keeping and why?}

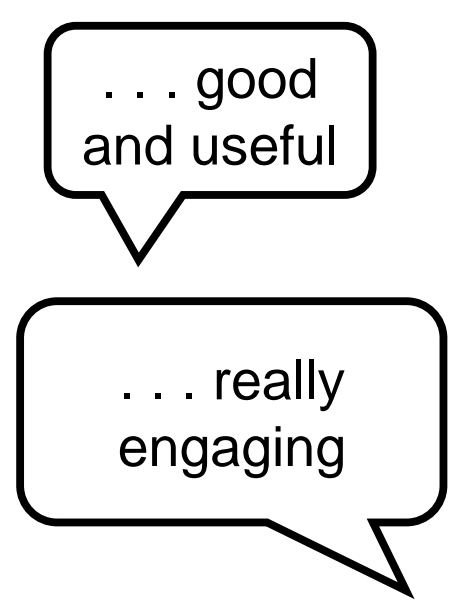

Small group discussions rather than large group discussions

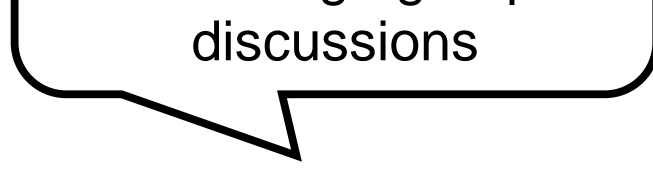

I loved the Thursday discussions we would do in small groups with a T.A. because it allowed us to discuss the contents of the module for that week and use the material in real world scenarios.
The Thursday group zoom calls because they were very engaging and I, personally, enjoyed these and learned a lot and not just about the course but about others, as well; including how their lives were applicable to concepts within this class/the textbook.

\section{$45 \%$}

mentioned T.A. led small group discussions

I really loved the aspect of having a full class lecture on Tuesdays, and then the group discussions on Thursdays. I am someone who learns a lot better in smaller groups, and I was worried that I would have trouble understanding the material when it was completely lecture with $\mathbf{8 0}$ or so other students. The group discussions really cemented my learning and were very beneficial when it came to my understanding of course material. 


\section{Which aspects of the course would you recommend changing and why?}

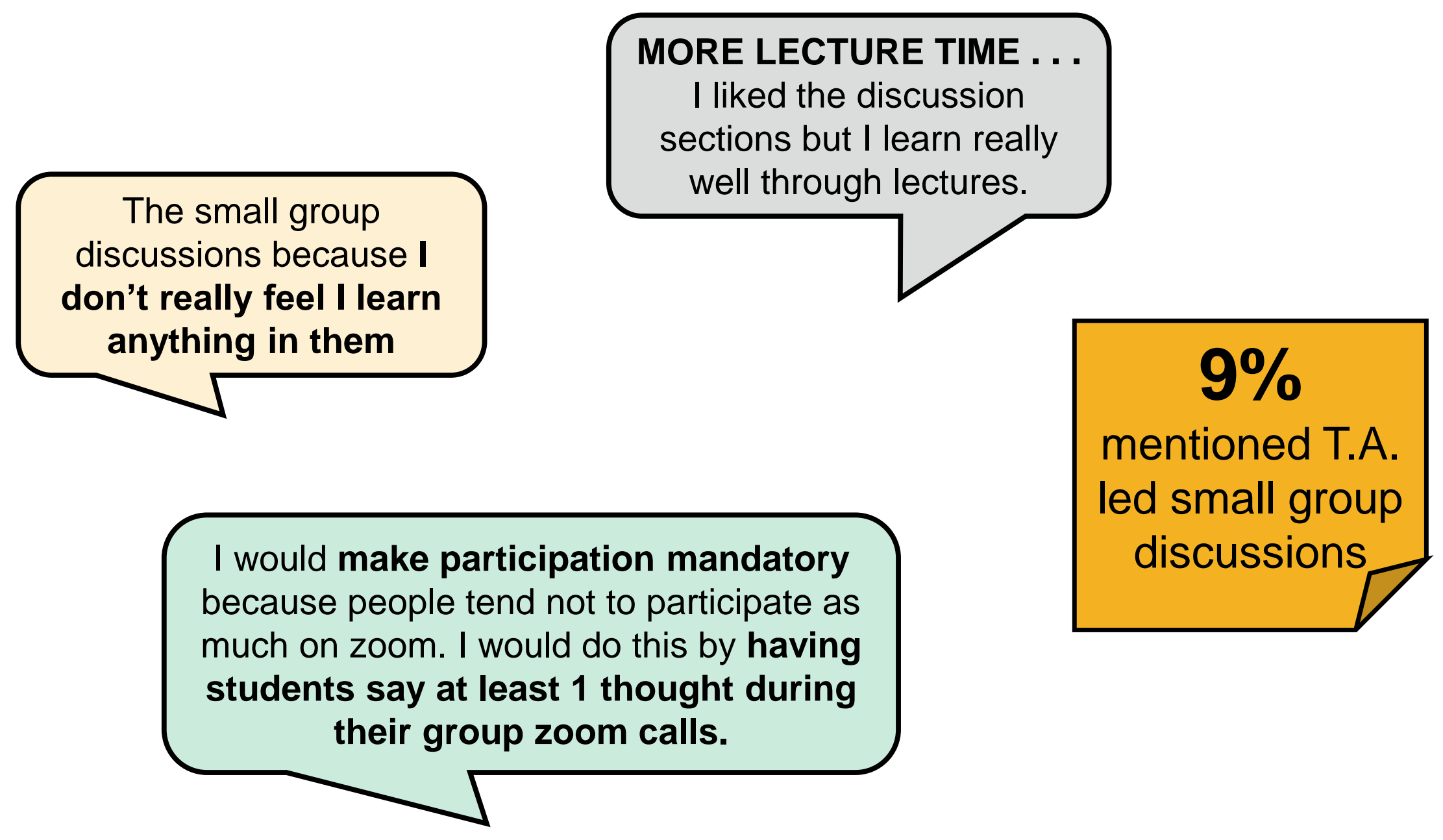




\section{Evaluating TA Experience}

\section{Post-Assistantship Reflections}

$\star$ Created community

$\star$ Increased confidence

$\star$ Deepened knowledge

$\star$ Promoted professionalism

$\star$ Crystallized career goals $\star 2$ SoTL research projects

$\star$ Mentors for "new" TAs

$\star$ Implementing suggestions 


\section{Benefits?}

\section{Best \\ practices?}

$\star$ Inclusive community

$\star$ Ground rules for democratic discussions

$\star$ Active learning

$\star$ Leadership and professional development

$\star$ Community before content

$\star$ Training not grading 


\section{Questions?}

cstricklandhughes@pacific.edu

Gratefully acknowledge support from:

- STEM FLC

- CTL

- COP CRF
- Colleagues

- TAs

- Students 